\title{
Ocular biometric characteristics of cataract patients in western China
}

\author{
Qing Huang, Yongzhi Huang, Qu Luo and Wei Fan*
}

\begin{abstract}
Background: We aimed to measure ocular biometric characteristics in older cataract patients from western China.

Methods: Ocular biometry records were retrospectively analyzed for 6933 patients with cataracts (6933 eyes) at least 50 years old who were treated at West China Hospital of Sichuan University.

Results: Partial coherence laser interferometry gave the following population averages: axial length (AL), $24.32 \pm 2$. $42 \mathrm{~mm}$; anterior chamber depth (ACD), $3.08 \pm 0.47 \mathrm{~mm}$; keratometric power (K), $44.23 \pm 1.66$ diopters; and corneal astigmatism (CA), $1.00 \pm 0.92$ diopters. The percentage of individuals with $\mathrm{AL}>26.5 \mathrm{~mm}$ was $13.66 \%$, while the percentage with CA $>1.0$ diopters was $35.54 \%$. Mean AL and ACD showed a trend of decrease with increasing age $(P<0.001)$. AL correlated positively with ACD (Spearman coefficient, 0.542$)$ and CA $(0.111)$, but negatively with $\mathrm{K}(-0.411)$ (all $P<0.01)$. $\mathrm{K}$ also correlated negatively with $\operatorname{ACD}(-0.078, P<0.01)$.
\end{abstract}

Conclusions: These results show, for the first time, that older cataract patients from western China have similar ocular biometric characteristics as other populations. The high prevalence of severe axial myopia warrants further investigation.

Keywords: Axial length, Anterior chamber depth, Keratometric power, Corneal astigmatism, Myopia, IOL master

\section{Background}

Cataract surgery is the most commonly performed surgical procedure worldwide. Advances in surgical instruments and intraocular lens design have increased the expectations of surgeons and patients for satisfactory postoperative refractive results. To achieve this goal, accurate biometric measurements are crucial. The ocular biometric characteristics of a population, including axial length (AL), anterior chamber depth $(\mathrm{ACD})$, keratometric power $(\mathrm{K})$ and corneal astigmatism (CA), are important to know in order to help engineers design intraocular lenses and to help surgeons select the most appropriate lenses for patients. Partial coherence laser interferometry is used most frequently in the clinic to determine these parameters, and it is routinely used to calculate lens implant power for cataract surgery $[1,2]$.

Studies have described ocular biometric characteristics of various populations [3-12], including several from China [10-12]. To our knowledge, the values of ocular biometry parameters have never been published for

\footnotetext{
* Correspondence: fanwei55@yahoo.com

Department of Ophthalmology, West China Hospital of Sichuan University, Sichuan Province, Chengdu, China
}

populations from western China. The present work provides the first hospital-based population study of ocular biometric characteristics of cataract patients $50 \mathrm{yr}$. and older from western China.

\section{Methods}

Medical records were retrospectively reviewed for a consecutive series of patients aged 50 years and older with cataracts treated at West China Hospital of Sichuan University (Chengdu, China) from November, 2011 to August, 2014. Patients who lived outside western China or who underwent photorefractive surgery were excluded, as were patients with retinal detachment, eye trauma, eyeball atrophy, or severe cataracts that could not be analyzed using the IOL Master device. The study was carried out in accordance with the Declaration of Helsinki. The study protocol was approved by the Ethics Committee of the West China Hospital of Sichuan University (2016-324), and procedures were performed in accordance with relevant guidelines and regulations.

Ocular biometry was performed using the IOL Master system (IOL Master 500, Carl Zeiss Meditec AG, Jena, 
Germany), which uses signals from the tear film and retinal pigment epithelium to measure AL. AL measurements were performed a minimum of five times in each eye, the $\mathrm{AL}$ was obtained from the composite mean value of five measurements. ACD was defined as the distance from the anterior corneal surface to the anterior lens surface, and it was measured a minimum of five times. Minimal K (K1) and maximal K (K2) were determined at the maximal and minimal radii of curvature, and the two values were averaged to obtain K. Keratometric measurements were also taken three times. CA was calculated as the absolute difference between $\mathrm{K}$ values at the two meridians. We classified astigmatism as "with-the-rule" (WTR) when the steep meridian on the corneal surface was 60-120 degrees, or "against-therule" (ATR) when the steep meridian was $0-30$ degrees or 150-180 degrees [10,13]. Other cases of astigmatism were classified as oblique. Since biometric characteristics were similar within pairs of eyes [3], the right or left eye of each patient was randomly selected for all analyses. Similar results were obtained when data from only the right eyes of all patients were used (data not shown).

Statistical analyses were performed using SPSS 19.0 (IBM, USA). Only patients with complete data were included in analyses. Normality of data was tested for all variables using the Kolmogorov-Smirnov (K-S) test, which was taken to indicate skewed distribution if $P$ $<0.05$. Differences between two groups were assessed for significance using the $t$ test if data were normally distributed, and the Mann-Whitney $U$ test otherwise. Differences among more than two groups were assessed using analysis of variance (ANOVA) followed by the least-squares difference post-hoc test when data were normally distributed. When data were skewed, differences were assessed using the KruskalWallis test. Severe axial myopia was defined as AL longer than $26.5 \mathrm{~mm}$ in this study. Differences between groups in the percentage of severe axial myopia were assessed using the Pearson chi-squared test. Possible correlations between biometric parameters were assessed using Spearman's correlation coefficient, while possible associations among AL, ACD, K and $\mathrm{CA}$ were assessed using polynomial regression. The threshold of significance was defined as $P<0.05$.

\section{Results}

The final study population included 6933 cataract patients from western China (3311 men, 3622 women) ranging in age from 50 to 98 years. The population was divided into four age groups: $50-59 \mathrm{yr}$., $17.73 \%$ of the total population, mean age $55.40 \pm 2.98$ yr.; $60-69$ yr., $35.41 \%$, $64.68 \pm 2.92$ yr.; $70-79$ yr., $34.50 \%, 74.12 \pm 2$. 78 yr.; and $80+$ yr., $12.36 \%, 83.22 \pm 3.84$ yr.
Population distribution of ocular biometry characteristics Figure 1 shows the distribution of ocular biometric characteristics across the entire study population. The AL distribution (mean, $24.32 \pm 2.42 \mathrm{~mm}$ ) was positively skewed (1.914) and peaked, with kurtosis of 3.963 (K-S test, $P<0.001$ ). The ACD distribution (mean, $3.08 \pm 0$. $47 \mathrm{~mm}$ ) was normal (K-S test, $P=0.097$ ). The K distribution (mean, $44.23 \pm 1.66$ diopters [D]) was negatively skewed (-0.29), with kurtosis of 3.611 (K-S test, $P<0$. 001). The CA distribution (mean, $1.00 \pm 0.92 \mathrm{D})$ was skewed towards the right (5.485) and strongly peaked, with kurtosis of 73.32 (K-S test, $P<0.001$ ).

\section{Distribution of ocular biometry characteristics by sex}

Table 1 shows ocular biometry characteristics stratified by sex. Mean AL was significantly longer in men $(24.79 \pm 2$. $48 \mathrm{~mm})$ than in women $(23.88 \pm 2.27 \mathrm{~mm}, P<0.001)$, and $\mathrm{ACD}$ was deeper in men $(3.16 \pm 0.47$ vs $3.01 \pm 0.47 \mathrm{~mm}, P$ $<0.001)$. Conversely, mean $\mathrm{K}$ was significantly greater in women $(44.56 \pm 1.61$ vs $43.87 \pm 1.65 \mathrm{D}, P<0.001)$. Mean CA was similar between men and women $(0.99 \pm 0.84$ vs $1.0 \pm 0.99 \mathrm{D}, P=0.398)$.

\section{Distribution of ocular biometry characteristics by age} Mean AL and ACD showed a trend of decrease with increasing age (both $\mathrm{P}<0.001$; Table 2, Figs. 2 and 3). While CA varied significantly between some age groups $(P<0.001$; Table 2, Fig. 4$)$, there were no differences between others (age group 50-59 and 60-69, $P=0.143$; group $50-59$ and $70-79, P=0.091$ ), suggesting there was no trend change with age. The percentage of patients with $\mathrm{AL}>26.5 \mathrm{~mm}$ also showed a trend of decrease with increasing age $(P<0.001$, Table 3$)$. The percentage was $13.66 \%$ across the entire population (Table 3 ), and it rose to $21.72 \%$ in the youngest patient group (50-59 years). Furthermore, $9.29 \%$ of all patients had $\mathrm{AL}>28 \mathrm{~mm}$ (Table 4). In addition, it was noted that, in the group of patients with $\mathrm{AL}>26.5 \mathrm{~mm}$, male accounted for $58.82 \%$ (Table 3).

\section{Corneal astigmatism: Severity, type and variation with age}

Corneal astigmatism was less than $0.5 \mathrm{D}$ in $26.94 \%$ of eyes, $0.5-1.0 \mathrm{D}$ in $37.52 \%, 1.0-2.0 \mathrm{D}$ in $27.03 \%, 2.0-3.0$ $\mathrm{D}$ in $5.76 \%$, and $>3.0 \mathrm{D}$ in $2.75 \%$ (Fig. 5). It was WTR in $34.76 \%$ of eyes, ATR in $44.09 \%$, and oblique in $21.15 \%$. The distributions of astigmatism axes varied significantly with age $(P<0.001$, Fig. 6). The percentage of patients with WTR astigmatism decreased with age, while the percentage with ATR astigmatism increased with age.

\section{Correlations between ocular biometric characteristics}

AL correlated positively with ACD (Spearman coefficient, 0.542$)$ and with CA (0.111), but negatively with $\mathrm{K}$ 


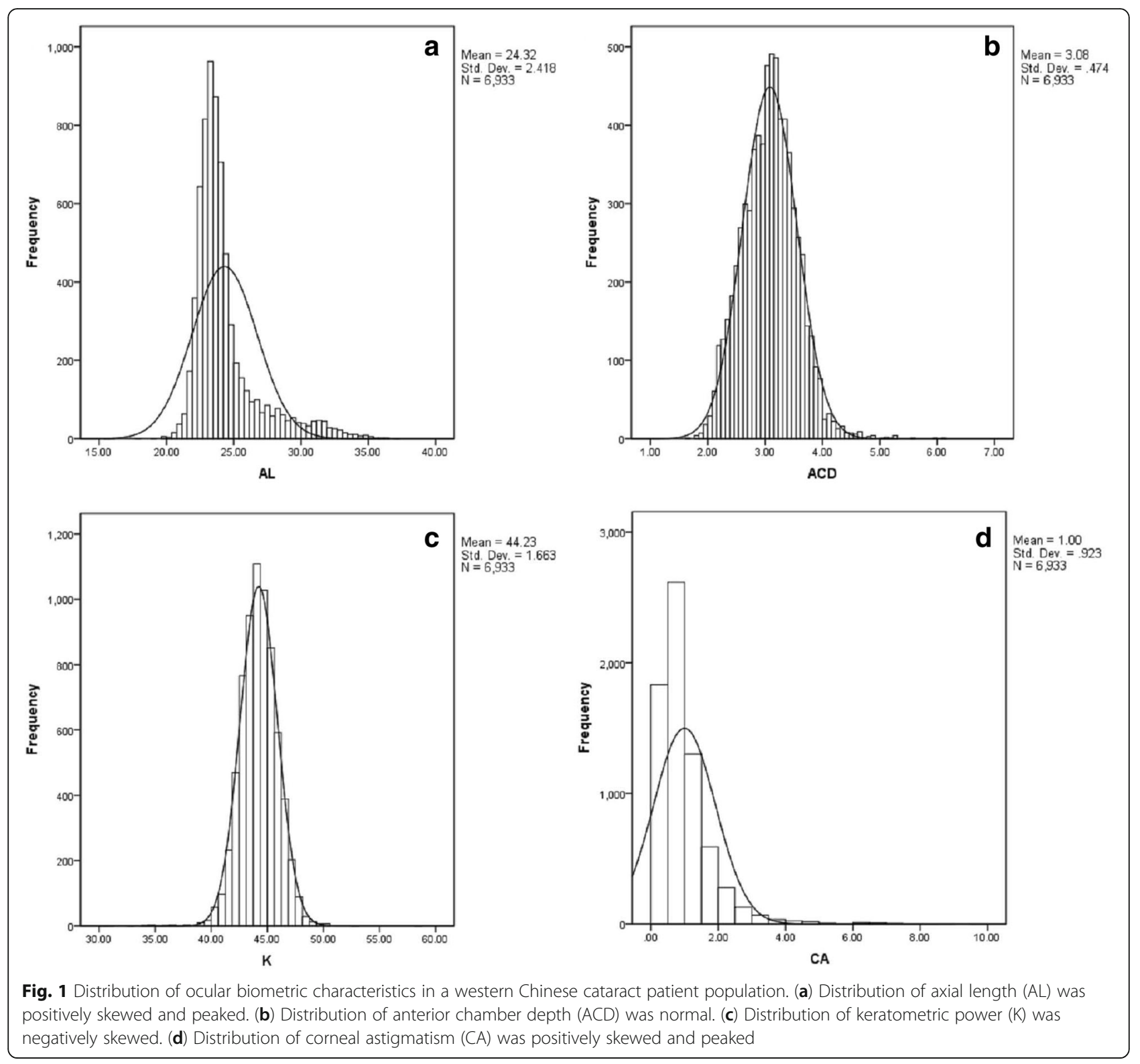

Table 1 Ocular biometric characteristics of western Chinese adult cataract patients, stratified by sex

\begin{tabular}{lllll}
\hline Gender & AL $(\mathrm{mm})$ & $\mathrm{ACD}(\mathrm{mm})$ & $\mathrm{K}(\mathrm{D})$ & $\mathrm{CA}(\mathrm{D})$ \\
\hline Male $(n=3311)$ & $24.79 \pm 2.48$ & $3.16 \pm 0.47$ & $43.87 \pm 1.65$ & $0.99 \pm 0.84$ \\
Female $(n=3622)$ & $23.88 \pm 2.27$ & $3.01 \pm 0.47$ & $44.56 \pm 1.61$ & $1.0 \pm 0.99$ \\
Total $(n=6933)$ & $24.32 \pm 2.42$ & $3.08 \pm 0.47$ & $44.23 \pm 1.66$ & $1.0 \pm 0.92$ \\
$\mathrm{P}^{\mathrm{a}}$ & $<0.001^{\mathrm{b}}$ & $<0.001^{\mathrm{c}}$ & $<0.001^{\mathrm{b}}$ & $0.398^{\mathrm{b}}$ \\
\hline
\end{tabular}

Difference between males and females

bMann-Whitney U-test

${ }^{c} t$ test
(-0.411) (all $P<0.01$; Table 5 ). K correlated negatively with ACD $(-0.078, P<0.01)$ and positively with CA $(0$. 054, $P<0.01)$. ACD correlated negatively with CA $(-0$. 003, $P=0.79$ ). ACD showed an increasing trend when AL fell below $29.9 \mathrm{~mm}$ (Fig. 7a), while $\mathrm{K}$ showed a decreasing trend when AL fell below $28.6 \mathrm{~mm}$ (Fig. 7b). CA increased with AL (Fig. 7c).

\section{Discussion}

Few studies have focused on large populations of Chinese cataract patients, especially from western China. This study aimed to describe a hospital-based distribution of ocular biometric parameters in western Chinese cataract patients. As most patients came from Sichuan which is the most heavily populated province in western China, the 
Table 2 Distribution of ocular biometric parameters by age group and sex

\begin{tabular}{ccccll}
\hline Age \& sex & $\mathrm{N}$ & $\mathrm{AL}(\mathrm{mm})$ & $\mathrm{ACD}(\mathrm{mm})$ & $\mathrm{K}(\mathrm{D})$ & $\mathrm{CA}(\mathrm{D})$ \\
\hline 50-59 yr & & & & & \\
Male & 535 & $25.4 \pm 3.07$ & $3.33 \pm 0.44$ & $43.66 \pm 1.76$ & $0.96 \pm 0.88$ \\
Female & 694 & $24.53 \pm 2.98$ & $3.21 \pm 0.44$ & $44.37 \pm 1.83$ & $1.0 \pm 1.18$ \\
Total & 1229 & $24.91 \pm 3.05$ & $3.26 \pm 0.45$ & $44.06 \pm 1.83$ & $0.98 \pm 1.06$ \\
60-69 yr & & & & & \\
Male & 1095 & $25.13 \pm 2.68$ & $3.25 \pm 0.44$ & $43.96 \pm 1.55$ & $0.95 \pm 0.85$ \\
Female & 1360 & $23.92 \pm 2.29$ & $3.06 \pm 0.45$ & $44.66 \pm 1.53$ & $0.91 \pm 0.89$ \\
Total & 2455 & $24.46 \pm 2.54$ & $3.14 \pm 0.46$ & $44.31 \pm 1.58$ & $0.93 \pm 0.88$ \\
70-79yr & & & & & \\
Male & 1183 & $24.49 \pm 2.12$ & $3.09 \pm 0.46$ & $44.01 \pm 1.5$ & $0.98 \pm 0.79$ \\
Female & 1209 & $23.62 \pm 1.87$ & $2.92 \pm 0.45$ & $44.65 \pm 1.69$ & $1.04 \pm 0.99$ \\
Total & 2392 & $24.05 \pm 2.04$ & $3.0 \pm 0.46$ & $44.28 \pm 1.61$ & $1.0 \pm 0.9$ \\
$>$ 80 yr & & & & & \\
Male & 498 & $24.12 \pm 1.76$ & $2.94 \pm 0.45$ & $43.87 \pm 1.65$ & $1.17 \pm 0.88$ \\
Female & 359 & $23.36 \pm 1.44$ & $2.76 \pm 0.43$ & $44.56 \pm 1.61$ & $1.2 \pm 0.9$ \\
Total & 857 & $23.81 \pm 1.67$ & $2.86 \pm 0.45$ & $44.23 \pm 1.61$ & $1.18 \pm 0.89$ \\
Pa & & $<0.001$ & $<0.001$ & 0.004 & $<0.001$ \\
\hline
\end{tabular}

${ }^{\mathrm{a}}$ Difference between age groups

results may be representative, to some extent, of the larger population of western China. In addition to providing a rich description of ocular characteristics to serve as a reference for future work, we found a high prevalence of severe axial myopia, particularly in relatively younger patients, which merits further study.

The AL distribution in our population showed positive skew and significant kurtosis, similar to that observed in a healthy Caucasian population [4], but different from that observed in healthy Singaporean Malays [9]. Mean $\mathrm{AL}$ was shorter in our population $(24.32 \pm 2.42 \mathrm{~mm})$ than in cataract patients from eastern China $(24.86 \pm$ $2.72 \mathrm{~mm}$ ) [14]. The possible explanation may be that

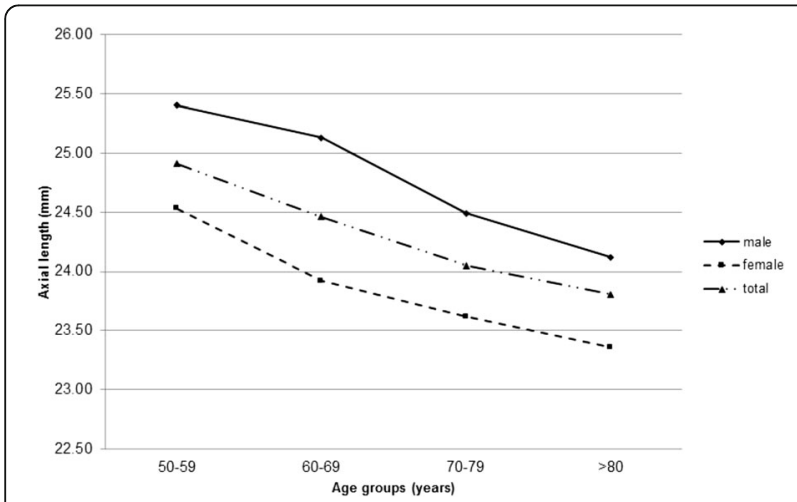

Fig. 2 Distribution of axial length across the four age groups of the cataract population. Mean axial length showed a decreasing trend with age

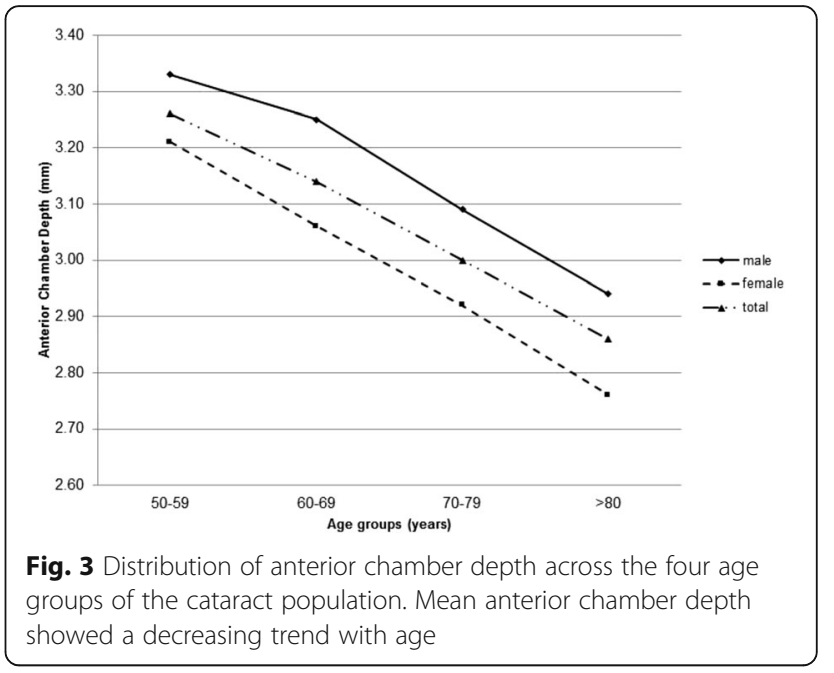

the previous study in eastern China [14] included patients aged 18-95 years old; their participants aged 18-49 yr. had longer AL than older participants, making their mean AL longer than ours. At the same time, mean AL was longer in our patients than in cataract patients from southern China $(24.07 \pm 2.14 \mathrm{~mm})[10]$ and in healthy individuals from southern China $(23.48 \mathrm{~mm})$ [15], Europe $(23.43 \pm 1.51 \mathrm{~mm})$ [5], Latin America $(23.38 \mathrm{~mm})$ [6], and other parts of Asia (23.13 $\pm 1.15 \mathrm{~mm}$ [7], $23.13 \pm$ $1.00 \mathrm{~mm} \mathrm{[8]} \mathrm{and} 23.55 \mathrm{~mm}$ [9]). One likely explanation for these differences between our study and others is ethnicity of Sichuan, which is one of the provinces with most populous ethnic groups of Han Chinese. Another explanation is the relatively high proportion of our cataract patients with severe axial myopia, often defined as $\mathrm{AL}>26.5 \mathrm{~mm}[16,17]$. Our hospital attracts many such patients from Sichuan and other neighbor provinces in western China. Indeed, the proportion of severely axial myopic eyes in our study (13.66\%), especially among those aged $50-59$ years $(21.72 \%)$, was higher than in a study of

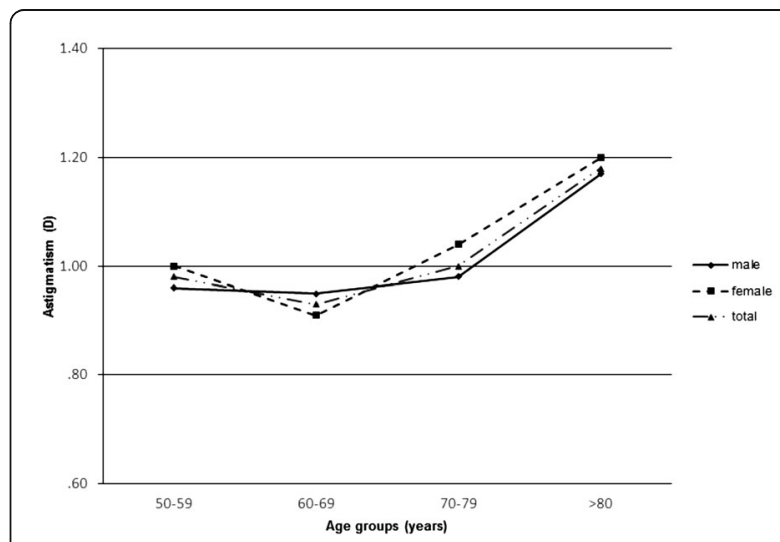

Fig. 4 Distribution of corneal astigmatism across the four age groups of the cataract population. Mean corneal astigmatism did not vary with age 
Table 3 Percentages of cataract patients with axial length > $26.5 \mathrm{~mm}$ in each age group

\begin{tabular}{lllllll}
\hline Age $(\mathrm{yr})$ & $\mathrm{n1}^{\mathrm{a}}$ & $\mathrm{n}^{\mathrm{b}}$ & $\mathrm{n} 1 / \mathrm{n} 2(\%)$ & $\mathrm{Nm}^{\mathrm{d}}$ & $\mathrm{Nf}$ & $\mathrm{Nm} / \mathrm{n} 1(\%)$ \\
\hline $50-59$ & 267 & 1229 & 21.72 & 140 & 127 & 52.43 \\
$60-69$ & 381 & 2455 & 15.52 & 230 & 151 & 60.37 \\
$70-79$ & 249 & 2392 & 10.41 & 153 & 96 & 61.45 \\
$>80$ & 50 & 857 & 5.83 & 34 & 16 & 68.0 \\
Total & 947 & 6933 & 13.66 & 557 & 390 & 58.82 \\
$\mathrm{P}^{c}$ & & & $<0.001$ & & &
\end{tabular}

${ }^{a}$ no. with axial length $>26.5 \mathrm{~mm}$ in this age group

${ }^{\mathrm{b}}$ Total $\mathrm{N}$ in this age group

'Difference between age groups

${ }^{\mathrm{d}}$ No. of male with axial length $>26.5 \mathrm{~mm}$ in this age group

${ }^{\mathrm{e}} \mathrm{No}$. of female with axial length $>26.5 \mathrm{~mm}$ in this age group

cataract patients from southern China (11.9\%) [10]. These results may suggest that patients with severe axial myopia tend to develop cataracts at a younger age and therefore require earlier cataract surgery $[10,18]$. In any event, our results are consistent with numerous reports of high global prevalence of myopia. In East Asian countries, this prevalence may reach $70-80 \%[11,12,19,20]$, with prevalence of severe myopia ranging from $8.4 \%$ to $38 \%$ $[11,21,22]$. In Western countries, prevalence of myopia ranges from $25 \%$ to $40 \%$ [23, 24].

$\mathrm{AL}$ in our population showed a gender bias: mean $\mathrm{AL}$ was longer in men $(24.79 \pm 2.48 \mathrm{~mm})$ than in women $(23.88 \pm 2.27 \mathrm{~mm})$. This echoes findings from studies of cataract populations in the US [25], among Singaporean Chinese [26], and among Chinese from the southern part of the mainland [10, 13]. Our result also echoes findings from studies of healthy eyes in Chinese from the southern part of the mainland [15], Latin Americans [6] and Icelanders [27]. The AL difference between men and women in our study $(0.91 \mathrm{~mm})$ was longer than that in the previous studies. This may be caused by the relatively high proportion of male patients with severe axial myopia (58.82\% in male vs $41.18 \%$ in female). In addition, many cross-sectional studies showed body height was positively correlated with AL, men had taller stature than women, and the association between male

Table 4 Distribution of anterior chamber depth (ACD) across patient subgroups with different axial lengths (AL)

\begin{tabular}{lll}
\hline AL $(\mathrm{mm})$ & $N(\%)$ & ACD $(\mathrm{mm})$ \\
\hline$<22$ & $348(5.02)$ & $2.6 \pm 0.41$ \\
$22-25$ & $5069(73.11)$ & $3.01 \pm 0.43$ \\
$25-28$ & $872(12.58)$ & $3.38 \pm 0.4$ \\
$>28$ & $644(9.29)$ & $3.51 \pm 0.41$ \\
Total & 6933 & $3.08 \pm 0.47$ \\
$\mathrm{P}^{\mathrm{a}}$ & & $<0.001$ \\
\hline
\end{tabular}

${ }^{\mathrm{a}}$ Difference between groups gender and longer AL may reflect the difference in stature between the sexes [3, 28-30].

We found that AL showed a trend of decrease with increasing age, as reported in cross-sectional studies from the UK [31, 32], US [33], and southern China [10]. Studies of Singaporeans suggest that this association may reflect that younger generations are generally taller, so it may be a cohort effect associated with improved nutrition [3, 34]. Other studies have proposed that the reduction of $\mathrm{AL}$ in the adult eye may serve as an emmetropizing mechanism, correlating with the increase in refractory power $[3,31]$. Another possible explanation, at least in our study, is that younger cataract patients are more likely to have axial myopia. Because of the cross-sectional nature of our study, our comparison of different age groups is confounded with generational effects, so prospective studies are needed to determine why AL decreases with age.

ACD showed normal distribution in our population, with greater depth occurring in male patients and younger patients. This is consistent with findings from other studies $[8,9,13,15,26]$. This variation of ACD with sex has been attributed to differences in stature, particularly height, between men and women $[4,26]$. The variation of ACD with age has been attributed to age-related lens thickening $[10,33]$, which may shift the iris forward, making the anterior chamber shallower [6]. Our finding of shallower ACD in older women is consistent with the higher prevalence of angle-closure glaucoma in this population [35]. The reported ability of cataract surgery to significantly deepen the anterior chamber [36] implies that older women with cataracts may benefit from earlier surgery [13]. Unfortunately, we could not verify whether cataract surgery deepened the anterior chamber in our population because the IOL Master system does not measure lens thickness or other relative ocular characteristics. Further study is needed to address this question directly.

The $\mathrm{K}$ distribution in our population was skewed. $\mathrm{K}$ did not clearly increase with age, in contrast to other studies $[37,38]$, and $\mathrm{K}$ was greater in women than men, similar to other studies [5, 9]. Greater mean $\mathrm{K}$ in women indicates higher corneal refractory power, which may be an emmetropizing mechanism to compensate for shorter AL.

CA did not increase or decrease with age as other studies [13, 37, 39, 40]. Consistent with the idea that many cataract patients suffer from corneal astigmatism, $35.54 \%$ of eyes in our population had CA $>1.0 \mathrm{D}$, with similarly high proportions reported in Spain (34.8\%) [40] and Japan (36.4\%) [41]. These results highlight the importance of astigmatism correction during cataract surgery. Toric intraocular lenses can correct corneal astigmatism of 0.7-8.4 D during cataract surgery [40], and such lenses are now widely used in China. Our 


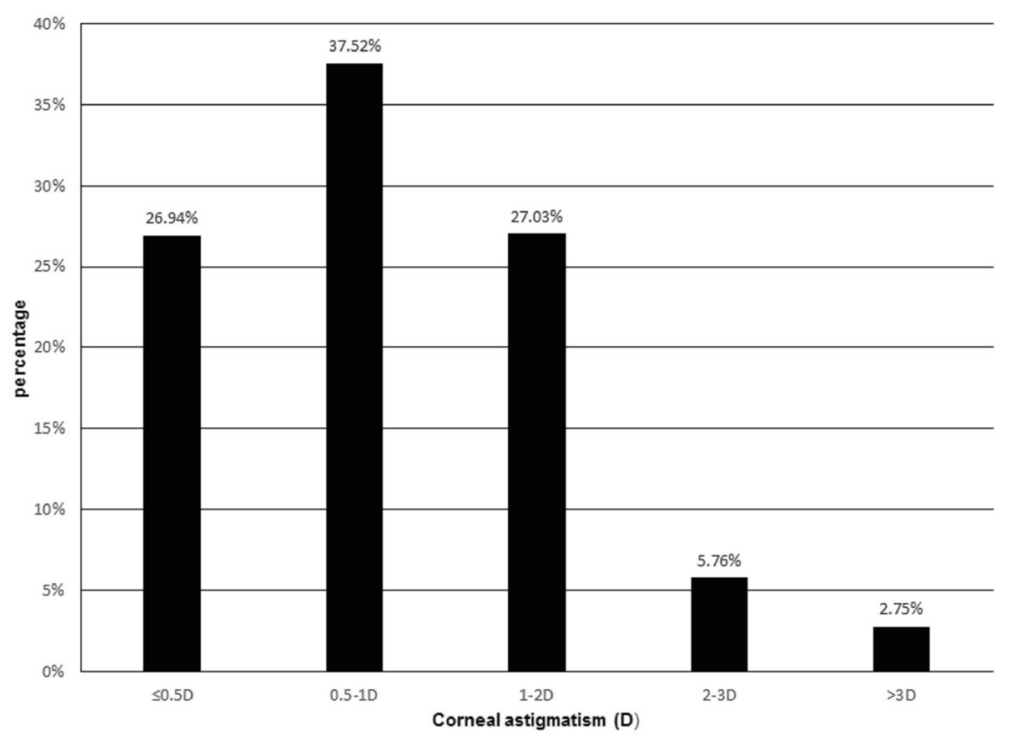

Fig. 5 Distribution of corneal astigmatism (in diopters, D) across the entire cataract population

results, together with those from other populations, may be of interest to hospitals and lens manufacturers.

Prevalence of WTR corneal astigmatism decreased with increasing age, while prevalence of ATR corneal astigmatism rose. Other studies have reported a similar age-related change in astigmatism axis [10, 13, 42]. This change has been attributed to extraocular muscle tension, visual feedback, corneal tissue degeneration, reduction in eyelid pressure and effects of intraocular pressure on corneal curvature [43]. These findings may help ophthalmologists take into account the effects of aging on the age-related change of astigmatism axis when selecting toric lenses.

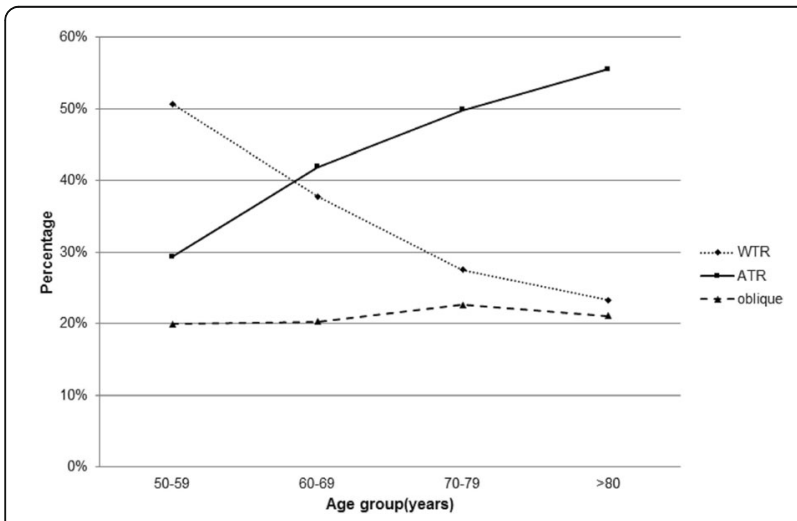

Fig. 6 Distribution of corneal astigmatism axes across the four age groups of the cataract population. Across all age groups, the prevalence of oblique astigmatism was lower than that of with-therule (WTR) or against-the-rule (ATR) astigmatism. The prevalence of WTR astigmatism showed a decreasing trend with age, whereas the prevalence of ATR astigmatism showed an increasing trend with age
$\mathrm{AL}$ in our population correlated positively with ACD, as reported in other work $[10,15,44]$, while it correlated negatively with $K$, as reported previously $[10,14,15,45]$. The positive correlation with ACD may reflect a tendency of shorter eyes to have smaller anterior chambers. The negative correlation with $\mathrm{K}$ may reflect a tendency of shorter eyes to have steeper corneas and longer eyes to have flatter corneas [45], suggesting an emmetropic mechanism.

While the present study appears to be the first description of ocular biometric characteristics in such a large population of cataract surgery candidates from western China, we cannot exclude selection bias because ours is a hospital-based population from a single medical center. This is particularly important to keep in mind when speculating about the reasons for the high prevalence of severe axial myopia in our patients, particularly younger ones. The fact that we examined 6933 patients suggests that our findings may be relevant to the broader population of individuals with cataracts in western China, although the IOL Master system can fail in $36-38 \%$ of patients with dense or posterior

Table 5 Pairwise correlations among axial length $(A L)$, anterior chamber depth (ACD), keratometric power (K) and corneal astigmatism (CA)

\begin{tabular}{llll}
\hline & ACD $(\mathrm{mm})$ & $\mathrm{K}(\mathrm{D})$ & $\mathrm{CA}(\mathrm{D})$ \\
\hline $\mathrm{AL}(\mathrm{mm})$ & $0.542^{\mathrm{a}}$ & $-0.411^{\mathrm{a}}$ & $0.111^{\mathrm{a}}$ \\
$\mathrm{ACD}(\mathrm{mm})$ & - & $-0.078^{\mathrm{a}}$ & $-0.003^{\mathrm{b}}$ \\
$\mathrm{K}(\mathrm{D})$ & - & - & $0.054^{\mathrm{a}}$ \\
\hline
\end{tabular}

$\mathrm{a} a<0.01$

${ }^{\mathrm{b}} P=0.79$ 

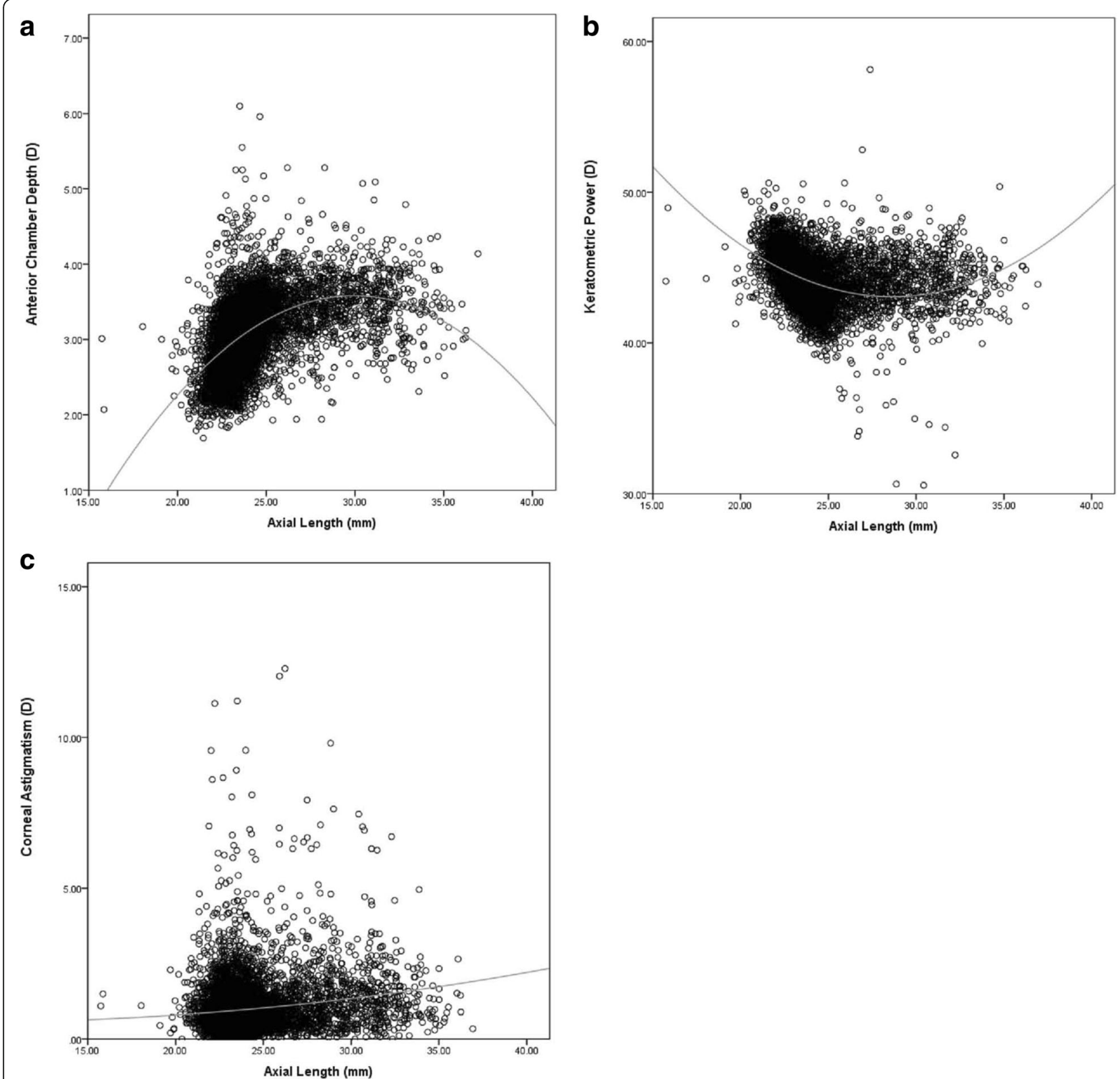

Fig. 7 Correlation of axial length with anterior chamber depth, corneal power or corneal astigmatism. (a) Anterior chamber depth increased with axial length up to a length of $29.9 \mathrm{~mm}$. (b) Keratometric power decreased with increasing axial length up to a length of $28.6 \mathrm{~mm}$. (c) Corneal astigmatism increased with axial length over the observed range of lengths

subcapsular cataracts [46, 47], and we excluded patients with severe cataracts. In addition, the retrospective nature of our study means that some relevant biometric parameters were not measured, limiting the analyses that we could perform. For example, cataract grading scale was unavailable for many patients in this retrospective study, and this parameter can influence ocular biometric characteristics $[6,48]$.

\section{Conclusion}

This study provides data on ocular biometric parameters and their relationships in a large, representative population of cataract patients at least 50 years old from western China. The present work helps expand the reference database on ocular biometric characteristics of Asian cataract populations. It also highlights the need for further studies into the factors that may contribute to the high prevalence of severe axial myopia. 


\section{Abbreviations}

ACD: Anterior chamber depth; AL: Axial length; ATR: Against-the-rule; CA: Corneal astigmatism; K: Keratometric power; K1: Minimal keratometric power; K2: Maximal keratometric power; WTR: With-the-rule

\section{Acknowledgments}

The authors thank ophthalmology technicians at West China Hospital for providing ocular biometric data, as well as Professor Jan Dietrich Reinhardt (Sichuan University) for helping revise the manuscript.

\section{Availability of data and materials}

The datasets generated and/or analyzed during the current study are not all publicly available in order to protect patient anonymity, but are available from the corresponding author on reasonable request.

\section{Authors' contributions}

WF conceived, designed and coordinated the study. QH analyzed and interpreted the data, and drafted the manuscript. YH helped prepare the data. QL participated in statistical analysis. All authors read and approved the final manuscript.

\section{Ethics approval and consent to participate}

The need for informed consent was waived by the Ethics Committee of the West China Hospital of Sichuan University because this was a retrospective study. The study protocol was approved by the Ethics Committee of the West China Hospital of Sichuan University (2016-324). The study was carried out in accordance with the Declaration of Helsinki.

\section{Competing interests}

The authors declare that they have no competing interests.

\section{Publisher's Note}

Springer Nature remains neutral with regard to jurisdictional claims in published maps and institutional affiliations.

\section{Received: 20 September 2017 Accepted: 10 April 2018} Published online: 17 April 2018

\section{References}

1. Hill W, Angeles R, Otani T. Evaluation of a new IOLMaster algorithm to measure axial length. J Cataract Refract Surg. 2008;34:920-4.

2. Suto C, Sato C, Shimamura E, Toshida H, Ichikawa K, Hori S. Influence of the signal-to-noise ratio on the accuracy of IOLMaster measurements. J Cataract Refract Surg. 2007:33:2062-6.

3. Wong TY, Foster PJ, Johnson GJ, Klein BE, Seah SK. The relationship between ocular dimensions and refraction with adult stature: the Tanjong Pagar survey. Invest Ophthalmol Vis Sci. 2001;42:1237-42.

4. Fotedar R, Wang JJ, Burlutsky G, Morgan IG, Rose K, Wong TY, Mitchell P. Distribution of axial length and ocular biometry measured using partial coherence laser interferometry (IOL master) in an older white population. Ophthalmology. 2010;117:417-23.

5. Hoffmann PC, Hutz WW. Analysis of biometry and prevalence data for corneal astigmatism in 23,239 eyes. J Cataract Refract Surg. 2010;36:1479-85.

6. Shufelt C, Fraser-Bell S, Ying-Lai M, Torres M, Varma R. Refractive error, ocular biometry, and lens opalescence in an adult population: the Los Angeles Latino eye study. Invest Ophthalmol Vis Sci. 2005;46:4450-60.

7. Wickremasinghe S, Foster PJ, Uranchimeg D, Lee PS, Devereux JG, Alsbirk $\mathrm{PH}$, Machin D, Johnson GJ, Baasanhu J. Ocular biometry and refraction in Mongolian adults. Invest Ophthalmol Vis Sci. 2004:45:776-83.

8. Mallen EA, Gammoh Y, Al-Bdour M, Sayegh FN. Refractive error and ocular biometry in Jordanian adults. Ophthalmic Physiol Opt. 2005;25:302-9.

9. Lim LS, Saw SM, Jeganathan VS, Tay WT, Aung T, Tong L, Mitchell P, Wong TY. Distribution and determinants of ocular biometric parameters in an Asian population: the Singapore Malay eye study. Invest Ophthalmol Vis Sci. 2010;51:103-9

10. Cui Y, Meng Q, Guo H, Zeng J, Zhang H, Zhang G, Huang Y, Lan J. Biometry and corneal astigmatism in cataract surgery candidates from southern China. J Cataract Refract Surg. 2014:40:1661-9.

11. Sun J, Zhou J, Zhao P, Lian J, Zhu H, Zhou Y, Sun Y, Wang Y, Zhao L, Wei Y, et al. High prevalence of myopia and high myopia in 5060 Chinese university students in shanghai. Invest Ophthalmol Vis Sci. 2012;53:7504-9.
12. He M, Zeng J, Liu Y, Xu J, Pokharel GP, Ellwein LB. Refractive error and visual impairment in urban children in southern China. Invest Ophthalmol Vis Sci. 2004:45:793-9.

13. Chen W, Zuo C, Chen C, Su J, Luo L, Congdon N, Liu Y. Prevalence of corneal astigmatism before cataract surgery in Chinese patients. J Cataract Refract Surg. 2013;39:188-92.

14. Feng $\mathrm{CL}$, Yuan $\mathrm{YZ}$, Yuan F, Ma XP, Zhang CH. Biometric analysis of adult cataract surgery candidates in shanghai, China. West Indian Med J. 2015;

15. Chen H, Lin H, Lin Z, Chen J, Chen W. Distribution of axial length, anterior chamber depth, and corneal curvature in an aged population in South China. BMC Ophthalmol. 2016;16:47.

16. Hayashi M, Ito Y, Takahashi A, Kawano K, Terasaki H. Scleral thickness in highly myopic eyes measured by enhanced depth imaging optical coherence tomography. Eye (Lond). 2013;27:410-7.

17. Liang IC, Shimada N, Tanaka Y, Nagaoka N, Moriyama M, Yoshida T, OhnoMatsui K. Comparison of clinical features in highly myopic eyes with and without a dome-shaped macula. Ophthalmology. 2015:122:1591-600.

18. Hoffer KJ. Axial dimension of the human cataractous lens. Arch Ophthalmol. 1993;111:914-8

19. Lin LL, Shih YF, Hsiao CK, Chen CJ. Prevalence of myopia in Taiwanese schoolchildren: 1983 to 2000. Ann Acad Med Singap. 2004:33:27-33.

20. Lee JH, Jee D, Kwon JW, Lee WK. Prevalence and risk factors for myopia in a rural Korean population. Invest Ophthalmol Vis Sci. 2013:54:5466-71.

21. Pan CW, Zheng YF, Anuar AR, Chew M, Gazzard G, Aung T, Cheng CY, Wong TY, Saw SM. Prevalence of refractive errors in a multiethnic Asian population: the Singapore epidemiology of eye disease study. Invest Ophthalmol Vis Sci. 2013;54:2590-8.

22. Wang TJ, Chiang TH, Wang TH, Lin LL, Shih YF. Changes of the ocular refraction among freshmen in National Taiwan University between 1988 and 2005. Eye (Lond). 2009;23:1168-9.

23. Kempen JH, Mitchell P, Lee KE, Tielsch JM, Broman AT, Taylor HR, Ikram MK, Congdon NG, O'Colmain BJ. The prevalence of refractive errors among adults in the United States, Western Europe, and Australia. Arch Ophthalmol. 2004;122:495-505.

24. Vitale $\mathrm{S}$, Sperduto RD, Ferris FL, 3rd. Increased prevalence of myopia in the United States between 1971-1972 and 1999-2004. Arch Ophthalmol 2009; 127:1632-1639.

25. Jivrajka R, Shammas MC, Boenzi T, Swearingen M, Shammas HJ. Variability of axial length, anterior chamber depth, and lens thickness in the cataractous eye. J Cataract Refract Surg. 2008;34:289-94.

26. Wong TY, Foster PJ, Ng TP, Tielsch JM, Johnson GJ, Seah SK. Variations in ocular biometry in an adult Chinese population in Singapore: the Tanjong Pagar survey. Invest Ophthalmol Vis Sci. 2001;42:73-80.

27. Olsen T, Arnarsson A, Sasaki H, Sasaki K, Jonasson F. On the ocular refractive components: the Reykjavik eye study. Acta Ophthalmol Scand. 2007:85:361-6.

28. Nangia V, Jonas JB, Matin A, Kulkarni M, Sinha A, Gupta R. Body height and ocular dimensions in the adult population in rural Central India. The Central India eye and medical study. Graefes Arch Clin Exp Ophthalmol. 2010;248: 1657-66.

29. Nangia V, Jonas JB, Sinha A, Matin A, Kulkarni M, Panda-Jonas S. Ocular axial length and its associations in an adult population of central rural India: the Central India eye and medical study. Ophthalmology. 2010;117:1360-6.

30. Yin $G$, Wang YX, Zheng ZY, Yang $H, X u$ L, Jonas JB, Beijing Eye Study G. Ocular axial length and its associations in Chinese: the Beijing eye study. PLoS One. 2012;7:e43172.

31. Grosvenor T. Reduction in axial length with age: an emmetropizing mechanism for the adult eye? Am J Optom Physiol Optic. 1987;64:657-63.

32. Leighton DA, Tomlinson A. Changes in axial length and other dimensions of the eyeball with increasing age. Acta Ophthalmol. 1972;50:815-26.

33. Brown NP, Koretz JF, Bron AJ. The development and maintenance of emmetropia. Eye (Lond). 1999;13(Pt 1):83-92.

34. Saw SM, Chua WH, Hong CY. Wu HM, chia KS, stone RA, tan D. Height and its relationship to refraction and biometry parameters in Singapore Chinese children. Invest Ophthalmol Vis Sci. 2002;43:1408-13.

35. Salmon JF. Predisposing factors for chronic angle-closure glaucoma. Prog Retin Eye Res. 1999;18:121-32.

36. Lee RY, Kasuga T, Cui QN, Huang G, Wang SY, Lin SC. Ethnic differences in intraocular pressure reduction and changes in anterior segment biometric parameters following cataract surgery by phacoemulsification. Clin Exp Ophthalmol. 2013;41:442-9. 
37. KhabazKhoob M, Hashemi H, Yazdani K, Mehravaran S, Yekta A, Fotouhi A. Keratometry measurements, corneal astigmatism and irregularity in a normal population: the Tehran eye study. Ophthalmic Physiol Opt. 2010;30:800-5.

38. Eysteinsson T, Jonasson F, Sasaki H, Arnarsson A, Sverrisson T, Sasaki K, Stefansson E. Central corneal thickness, radius of the corneal curvature and intraocular pressure in normal subjects using non-contact techniques: Reykjavik eye study. Acta Ophthalmol Scand. 2002;80:11-5.

39. Khan Ml, Muhtaseb M. Prevalence of corneal astigmatism in patients having routine cataract surgery at a teaching hospital in the United Kingdom. J Cataract Refract Surg. 2011;37:1751-5.

40. Ferrer-Blasco T, Montes-Mico R, Peixoto-de-Matos SC, Gonzalez-Meijome JM Cervino A. Prevalence of corneal astigmatism before cataract surgery. J Cataract Refract Surg. 2009;35:70-5.

41. Miyake T, Kamiya K, Amano R, Shimizu K. Corneal astigmatism before cataract surgery. Nihon Ganka Gakkai Zasshi. 2011;115:447-53.

42. Yuan $X$, Song $H$, Peng G, Hua X, Tang X. Prevalence of corneal astigmatism in patients before cataract surgery in northern China. J Ophthalmol 2014; 2014:536412.

43. Read SA, Collins MJ, Carney LG. A review of astigmatism and its possible genesis. Clin Exp Optom. 2007;90:5-19.

44. Hosny M, Alio JL, Claramonte P, Attia WH, Perez-Santonja JJ. Relationship between anterior chamber depth, refractive state, corneal diameter, and axial length. J Refract Surg. 2000;16:336-40.

45. Jonas JB, Nangia V, Sinha A, Gupta R. Corneal refractive power and its associations with ocular and general parameters: the Central India eye and medical study. Ophthalmology. 2011;118:1805-11.

46. McAlinden C, Wang Q, Pesudovs K, Yang X, Bao F, Yu A, Lin S, Feng Y, Huang J. Axial length measurement failure rates with the IOLMaster and Lenstar LS 900 in eyes with cataract. PLoS One. 2015;10:e0128929.

47. McAlinden C, Wang Q, Gao R, Zhao W, Yu A, Li Y, Guo Y, Huang J. Axial length measurement failure rates with biometers using swept-source optical coherence tomography compared to partial-coherence interferometry and optical low-coherence interferometry. Am J Ophthalmol. 2017;173:64-9

48. Kubo E, Kumamoto Y, Tsuzuki S, Akagi Y. Axial length, myopia, and the severity of lens opacity at the time of cataract surgery. Arch Ophthalmol. 2006;124:1586-90.

Ready to submit your research? Choose BMC and benefit from:

- fast, convenient online submission

- thorough peer review by experienced researchers in your field

- rapid publication on acceptance

- support for research data, including large and complex data types

- gold Open Access which fosters wider collaboration and increased citations

- maximum visibility for your research: over $100 \mathrm{M}$ website views per year

At BMC, research is always in progress.

Learn more biomedcentral.com/submissions 